\title{
Evaluation of Antioxidant Activity and Inhibition of Tyrosinase Activity of Raphanus sativus var. caudatus Alef Extract
}

\author{
Panadda YONGPRADOEM ${ }^{1}$ and Natthida WEERAPREEYAKUL ${ }^{2, *}$ \\ ${ }^{I}$ Graduate School (in the Program of Aesthetic Sciences and Health), Faculty of Pharmaceutical Sciences, \\ Khon Kaen University, Khon Kaen 40002, Thailand \\ ${ }^{2}$ Division of Pharmaceutical Chemistry, Faculty of Pharmaceutical Sciences, Khon Kaen University, \\ Khon Kaen 40002, Thailand
}

('Corresponding author's email: natthida@kku.ac.th)

Received: 5 May 2018, Revised: 10 October 2018, Accepted: 15 November 2018

\begin{abstract}
This study was aimed to determine antioxidant and tyrosinase inhibition effects of the pod of Raphanus sativus L. var. caudatus Alef extract. The compounds consisted in the extracts were identified by HPLC from standard peak comparison. Pod was extracted by using 2 different solventsdichloromethane (DCM) and water. The antioxidant activity was evaluated based on free radical scavenging (DPPH) activity and ferric reducing ability (FRAP) assay. The lightening effect was determined from the inhibition of mushroom tyrosinase in vitro. The results showed that DCM extract contained sulforaphene, protocatechuic acid, $p$-hydroxybenzoic acid, caffeic acid, and ferulic acid. The aqueous extract contained sulforaphene, protocatechuic acid, $p$-hydroxybenzoic acid, caffeic acid, vanillic acid, and $p$-coumaric acid. The $\mathrm{DPPH}^{\bullet}$ scavenging effect expressed as the $\mathrm{IC}_{50}$ values for $\mathrm{DCM}$ and aqueous extracts were $883.38 \pm 22.9$ and $1,160.49 \pm 22.30 \mu \mathrm{g} / \mathrm{mL}$, respectively. The reducing power of aqueous extract $\left(218.27 \pm 0.010 \mu \mathrm{M} \mathrm{FeSO}_{4}\right.$ equivalent $)$ was greater than DCM extract $(166.34 \pm 0.018$ $\mu \mathrm{M} \mathrm{FeSO}_{4}$ equivalent) at the same concentration $(2,000 \mu \mathrm{g} / \mathrm{mL})$. However, both extracts showed lesser antioxidant activity than gallic acid, a positive control. DCM extract showed higher tyrosinase inhibitory effect than aqueous extract but lesser than kojic acid, a positive control. Both extracts at 2,000 $\mu \mathrm{g} / \mathrm{mL}$ concentration exerted 42 and $19 \%$ tyrosinase inhibition, respectively. In conclusion, the extraction solvent yielded different chemical constituents and thus the activities. The DCM extract exerted greater antioxidant activity and tyrosinase inhibition activity than the aqueous extract. The extract fractionation is required to get higher yields of bioactive compounds prior to further study and for cosmetics product development.
\end{abstract}

Keywords: HPLC, Antioxidant, Antityrosinase, Raphanus sativus var. caudatus Alef, Thai rat-tailed radish

\section{Introduction}

In the present, the cosmetic formulated from natural ingredient has gained interest. The beauty facial products are mostly for reducing freckles or dark spot, curing acne or providing moisturizing effect for anti-aging. Some of these products may contain hazardous substances, such as hydroquinone; when it is used higher than the regulate amount $(2 \%)$, it may cause skin irritation and may develop cancer [1]. Several studies have reported the detection of mercury, vitamin A derivative and steroid in some cosmetic products [1]. Mercury can cause burning sensation of the skin, contact dermatitis, nail discoloration [1], irritant, renal damage and neuropsychiatric symptoms [2]. Vitamin A derivative causes erythema and desquamation [3]. While steroid causes facial erythema, telangiectasia, aggravation of existing lesions and hypertrichosis [4]. Therefore, the search for safer compounds has been conducted. 
Thai rat-tailed radish (Raphanus sativus Linn var. caudatus Alef; RS) is an indigenous Thai vegetable. Previous research reported that RS comprises of isothiocyanate compounds such as sulforaphane and sulforaphene [5,6]. The extracts of RS have been reported to possess many biological effects, se.g. anticancer action in colon cancer [6,7], lung cancer [8] and liver cancer [9], antioxidant activity [10], antifungal activity [11], antidepressant-like activity [12], and anti-leishmanial activity [13]. Previously, the freeze-dried juice of Raphanus sativus root showed tyrosinase inhibition effect $\left(\mathrm{IC}_{50}=\right.$ $3.09 \mathrm{mg} / \mathrm{mL})$ higher than the methanolic extract $\left(\mathrm{IC}_{50}=9.62 \mathrm{mg} / \mathrm{mL}\right)$ [14]. Since Thai rat-tailed radish is in the same species as Raphanus sativus, therefore, it is of interest to explore the inhibition of tyrosinase activity.

In addition, phenolics are primary compounds found in many plants including Brassicaceae [15] and act as antioxidant-a desirable antiaging effect for cosmetic purpose. However, these compounds have yet been reported in Thai rat-tailed radish. In the present study, we identified the presence of phenolics and isothiocyanates (i.e., sulforaphane and sulforaphene) in the RS pod extract. The in vitro antioxidant was investigated from free radical scavenging (DPPH) ability and ferric reducing ability (FRAP) assay, while the lightening effect was determined from the mushroom tyrosinase inhibition.

\section{Materials and methods}

\section{Chemicals}

The commercial grade of dichloromethane (DCM) and the HPLC grade of glacial acetic acid, tetrahydrofuran (THF) and acetonitrile were purchased from V.S. Chem House (Bangkok, Thailand). Dimethyl sulfoxide (DMSO) (analytical grade) was purchased from Fisher Scientific (Loughborough, UK). Deionized (DI) water for HPLC analysis was from PURELAB option-Q (England). Pure D, Lsulforaphane was from Calbiochem (EMD, Darmstadt, Germany). L-sulforaphene was purchased from Enzo Life Science (NY, USA). Standards gallic acid, 3,4-dihydroxybenzoic acid (protocatechuic acid), $p$ hydroxybenzoic acid, chlorogenic acid, vanillic acid, caffeic acid, syringic acid, $p$-coumaric acid and ferulic acid, mushroom tyrosinase enzyme and 3,4-dihydroxy-L-phenylalanin (L-DOPA), 2,2-Diphenyl-1picrylhydrazyl, Iron(III) chloride and 2,4,6,-tris(2-pyridyl)-S-triazine were purchased from Sigma-Aldrich Co. (St. Louis, MO, USA). Kojic acid was from TCI (Tokyo, Japan). Methanol (analytical grade) was from Ajax Finechem Pty Ltd (NSW, Australia), hydrochloric acid 37\% was from QReC (New Zealand). Sodium acetate trihydrate was from Okhla Industrial Area, Phase-I (New Delhi, India).

\section{The extract preparation}

The RS pod was collected from Northern Thailand in 2017 and prepared for the extraction [16]. After washing and dry on sheet, the RS pod was cut in small pieces and homogenized in DI water at a ratio of $1: 1(\mathrm{w} / \mathrm{v})$. The homogenate was kept at room temperature for $2 \mathrm{~h}$ before filtration. The filtrate was divided in 2 portions. The first portion was filtered with Whatman ${ }^{\mathrm{TM}}$ No. 4 through Büchner funnel and vacuum pump. The water was removed from filtrate by a freeze dryer yielding dry aqueous crude extract $\left(2.869 \% \mathrm{w} / \mathrm{w}\right.$ fresh weight). The extract was stored before the freezing process at $-18{ }^{\circ} \mathrm{C}$ and subsequent decreasing the temperature to $-45^{\circ} \mathrm{C}$ in ethanol bath. The frozen extract was subjected to the freeze dryer at the temperature below $-100{ }^{\circ} \mathrm{C}$ under pressure below $0 \mathrm{~Pa}$ until obtaining the freeze-dried product of extract. The second portion was partitioned by using DCM thrice with the same water phase at a ratio of 1:1 (v/v). The lower DCM layer was collected and the contaminated water was removed by adding sodium sulfate anhydrous and then filtered. The DCM was removed under vacuum by rotary evaporator. The dry residue was purged with nitrogen gas and dried by using vacuum drying oven to yield dry crude DCM extract $\left(0.062 \% \mathrm{w} / \mathrm{w}\right.$ fresh weight). Both extracts were kept under $-20{ }^{\circ} \mathrm{C}$ for further use.

\section{Identification of phenolic compounds}

Phenolics were identified by HPLC analysis comparing to commonly found nine phenolics standards [17]. In this study, we determined 2 types of phenolics: (I) hydroxybenzoic acid, which are (1) gallic acid, (2) 3,4-dihydroxybenzoic acid (protocatechuic acid), (3) p-hydroxybenzoic acid, (4) vanillic acid and (5) syringic acid; and (II) hydroxycinnamic acid, which are (6) chlorogenic acid, (7) caffeic acid, 
$p$-coumaric acid and (8) ferulic acid. Reverse phase-HPLC analysis of aqueous and DCM crude extracts $(50 \mathrm{mg} / \mathrm{ml})$ were performed by using HPLC Agilent 1100 Series (G1316A column compartment) with an Agilent 1100 Series G1315B diode array detector (Waldbronn, Germany), and reverse phase HiQ sil $\mathrm{C} 18 \mathrm{~W}$ column $(4.6 \times 250 \mathrm{~mm}$, i.d. $5 \mu \mathrm{m})$. The mobile phase consisted of purified water with acetic acid (solvent A) and acetonitrile (solvent B) at a flow rate of $0.8 \mathrm{~mL} / \mathrm{min}$. Gradient elution was performed as follows: from 0 to $5 \mathrm{~min}$, linear gradient from 5 to $9 \%$ solvent $\mathrm{B}$; from 5 to $15 \mathrm{~min}$, linear gradient from 9 to $11 \%$ solvent B; from 15 to $22 \mathrm{~min}$, linear gradient from 11 to $15 \%$ solvent $\mathrm{B}$; from 22 to $30 \mathrm{~min}$, linear gradient from 15 to $18 \%$ solvent B; from 30 to $38 \mathrm{~min}$, linear gradient from 18 to $23 \%$ solvent $\mathrm{B}$; from 38 to $43 \mathrm{~min}$, linear gradient from 22 to $80 \%$ solvent B; from 43 to $46 \mathrm{~min}$, linear gradient from 80 to $90 \%$ solvent B; from 46 to $55 \mathrm{~min}$, linear gradient from 90 to $95 \%$ solvent B; from 55 to $60 \mathrm{~min}$, linear gradient from 95 to $5 \%$ solvent B; from 60 to $65 \mathrm{~min}$ isocratic at $95 \%$ solvent $\mathrm{B}$ and a reequilibration period of 5 min with $5 \%$ solvent $\mathrm{B}$ between individual runs. The column temperature was $38{ }^{\circ} \mathrm{C}$ and the injection volume was $20 \mu \mathrm{L}$. To confirm the presence of identified compound, UV-diode array detection was set at $280 \mathrm{~nm}, 320 \mathrm{~nm}$ and $370 \mathrm{~nm}$ and the co-injection between phenolics standard $(10 \mathrm{mg} / \mathrm{mL})$ and the crude extract $(50 \mathrm{mg} / \mathrm{mL})$ was performed.

\section{Identification of isothiocyanates}

Reverse phase-HPLC analysis of RS pod aqueous and DCM crude extracts $(50 \mathrm{mg} / \mathrm{mL})$ was performed by using HPLC with a diode array detector, HiQ sil C18W column $(4.6 \times 250 \mathrm{~mm}$, i.d. $5 \mu \mathrm{m})$ [16]. The mobile phase was $5 \%$ THF in ultrapure water $(\mathrm{v} / \mathrm{v})$. The flow rate was stable at $1 \mathrm{~mL} / \mathrm{min}$ for $30 \mathrm{~min}$. UV-diode array detection was set at $210 \mathrm{~nm}$ to confirm the presence of sulforaphane and sulforaphene. The concentration of sulforaphane and sulforaphene used in the experiment were 0.016 to $0.25 \mathrm{mg} / \mathrm{mL}$, respectively.

\section{DPPH radical-scavenging activity}

The antioxidant activity of extracts was determined based on the basis of the scavenging activity of the stable 2,2-diphenyl-1-picrylhydrazyl (DPPH) radical [18]. Briefly, DPPH was dissolved in methanol and was added into each wells of 96-well plate (a final concentration of $200 \mu \mathrm{M}$ ). Various concentrations of DCM and aqueous extracts dissolved in DMSO was mixed in the ratio 1:1 with the DPPH ${ }^{\bullet}$ solution in a 96-well microplate. The reaction mixture was incubated in the dark for $30 \mathrm{~min}$ at room temperature and measured at $517 \mathrm{~nm}$ using a microplate reader. The scavenging activity of DPPH radical represented as $\mathrm{IC}_{50}$ value was calculated in term of mean $\pm \mathrm{SD}$. The positive control was gallic acid and standard compounds were sulforaphene and sulforaphane. Gallic acid was used in the concentration ranged from 0.1 to $5 \mu \mathrm{g} / \mathrm{mL}$.

\section{Ferric reducing antioxidant power (FRAP) assay}

The FRAP assay was based on the reduction of ferric-tripyridyltriazine complex ( $\left.\mathrm{Fe}^{3+}-\mathrm{TPTZ}\right)$ to a blue colored ferrous-tripyridyltriazine complex (Fe $\left.{ }^{2+}-\mathrm{TPTZ}\right)$ [19]. The FRAP reagent was freshly prepared by mixing $300 \mathrm{mM}$ acetate buffer $\mathrm{pH}$ 3.6, $10 \mathrm{mM}$ TPTZ 2,4,6,-tris(2-pyridyl)-S-triazine solution in $40 \mathrm{mM} \mathrm{HCl}, 20 \mathrm{mM} \mathrm{FeCl}_{3}$ at a ratio of 10:1:1 (v/v/v). Various concentrations of DCM and aqueous extract solution were prepared in DMSO. Gallic acid was used as a positive control. Gallic acid was used in the concentration ranged from 0.1 to $10 \mu \mathrm{g} / \mathrm{mL}$. The $\mathrm{FeSO}_{4} \cdot 7 \mathrm{H}_{2} \mathrm{O}$ (ranged from 3.60 to $89.92 \mu \mathrm{M}$ ) was used as the standard solution. The reaction mixture was incubated in the dark $30 \mathrm{~min}$ at room temperature and measured at $593 \mathrm{~nm}$ using a microplate reader. The antioxidant potential of the extracts was determined from ferric reducing antioxidant power (FRAP). The standard curve was plotted and the $\mathrm{FeSO}_{4}$ linear regression equation was used to calculate the FRAP values of sample represented as molar concentration of $\mathrm{FeSO}_{4}$.

Determination of mushroom tyrosinase inhibition activity

To assess the lightening effect of the extracts, the inhibition of tyrosinase activity-an enzyme in melanogenesis-was evaluated in vitro [20]. Mushroom tyrosinase in phosphate buffer $\mathrm{pH} 6.8$ was added into each wells of a 96-well plate (a final concentration of 54 units $/ \mathrm{mL}$ ). DCM and aqueous extracts 
dissolved in DMSO were pipetted into each well with the final concentrations ranged $0.2-4,000 \mu \mathrm{g} / \mathrm{mL}$. The L-DOPA substrate in phosphate buffer $\mathrm{pH} 6.8$ was added to the reaction mixture yielding final concentration of $4.5 \mathrm{mM}$. All of the reaction mixture was incubated at room temperature for 10 min and measured for dopachrome at $475 \mathrm{~nm}$ using a microplate reader. The concentration possessing $50 \%$ tyrosinase inhibition was calculated. The positive control was kojic acid and standard compounds were sulforaphene and sulforaphane. Kojic acid was used in the contraptions ranging from 4 to $20 \mu \mathrm{g} / \mathrm{mL}$.

\section{Statistical analysis}

All experiments were done in 3 - 5 replicates. Data is expressed as average and standard deviations $($ mean $\pm \mathrm{SD})$. The data was analyzed to compare between groups and control group by one-way ANOVA at $95 \%$ confidence intervals $(p$-value $<0.05)$.

\section{Results and discussions}

\section{Phytochemical identification}

HPLC chromatograms (Figure 1) and retention time (Table 1) are shown for phenolic standards. The DCM extract was found to contain (2) protocatechuic acid, (3) p-hydroxybenzoic acid, (6) caffeic acid, and (9) ferulic acid (Figure 2). The aqueous extract was found to contain (2) protocatechuic acid, (3) $p$-hydroxybenzoic acid, (5) caffeic acid, (6) vanillic acid, and (8) $p$-coumaric acid (Figure 3). Ferulic acid was only detected in the DCM extract, while vanillic acid and $p$-coumaric acid were only detected in the aqueous extract. It should be noted that the other unknown peaks were also appeared in the DCM extract and yet to be identified because their retention times were not matched with the standard phenolics at 3 wavelengths $(280,320$ and $370 \mathrm{~nm})$, and especially after the co-injection of the standard in the extract was performed. The amount of each phenolics per gram crude extract were calculated from peak height and summarized in Table 1.

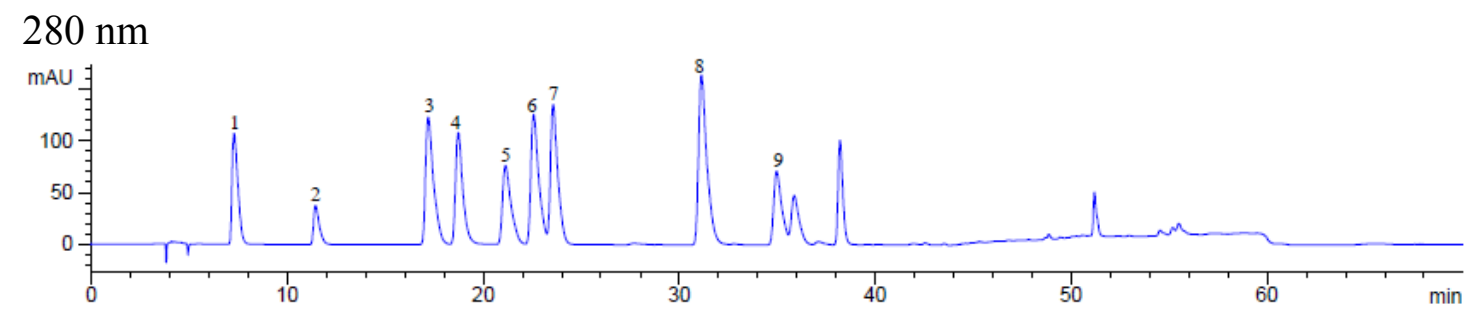

$320 \mathrm{~nm}$

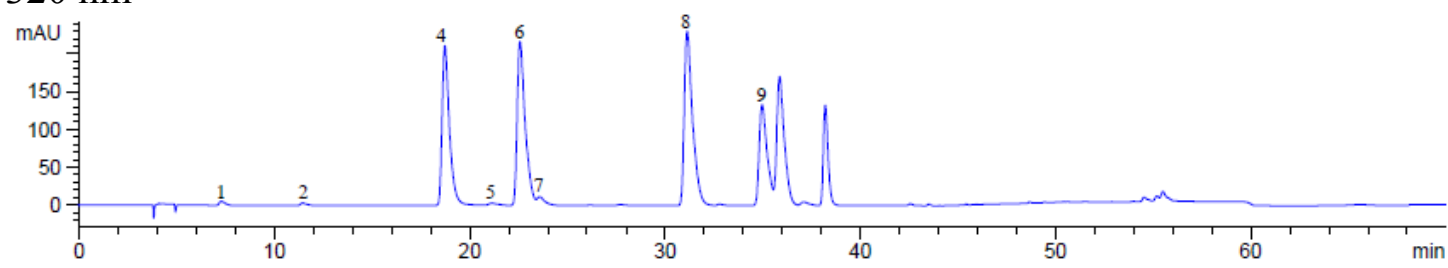

$370 \mathrm{~nm}$

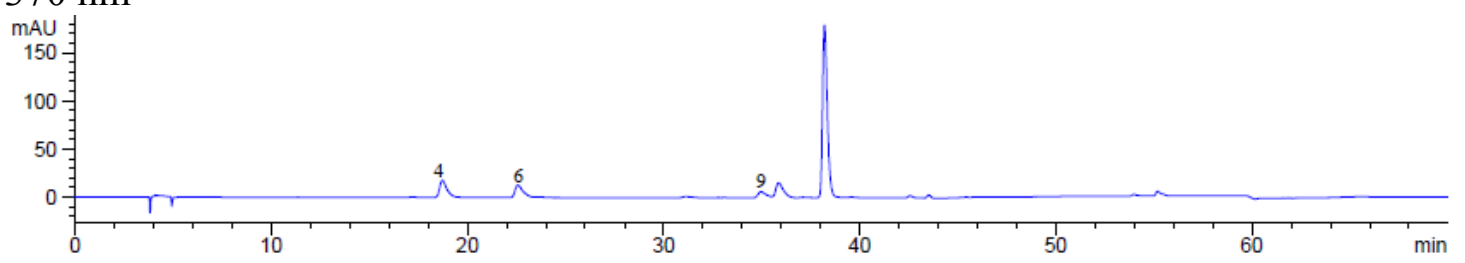

Figure 1 HPLC chromatograms of 9 phenolic standard compounds: (1) gallic acid (2) protocatechuic acid, (3) p-hydroxybenzoic acid, (4) chlorogenic acid, (5) vanillic acid, (6) caffeic acid, (7) syringic acid, (8) $p$-coumaric acid and, (9) ferulic acid. 
http://wjst.wu.ac.th

Moreover, the isothiocyanates contents were also determined because these compounds are commonly found in the Brassicaceae plant. HPLC chromatograms (Figure 4) of sulforaphene and sulforaphane standards at $210 \mathrm{~nm}$ showed the retention time at $23.84 \pm 0.10 \mathrm{~min}$ and $26.15 \pm 0.03 \mathrm{~min}$, respectively. DCM extract contained both sulforaphene and sulforaphane. Aqueous extract contained only sulforaphene. Sulforaphene content in DCM and aqueous extracts were $5.11 \pm 0.23 \mathrm{mg} / \mathrm{g}$ extract and 0.72 $\pm 0.02 \mathrm{mg} / \mathrm{g}$ extract, respectively. Although sulforaphane was identified, the content could not be calculated based on the poor resolution of peak area.

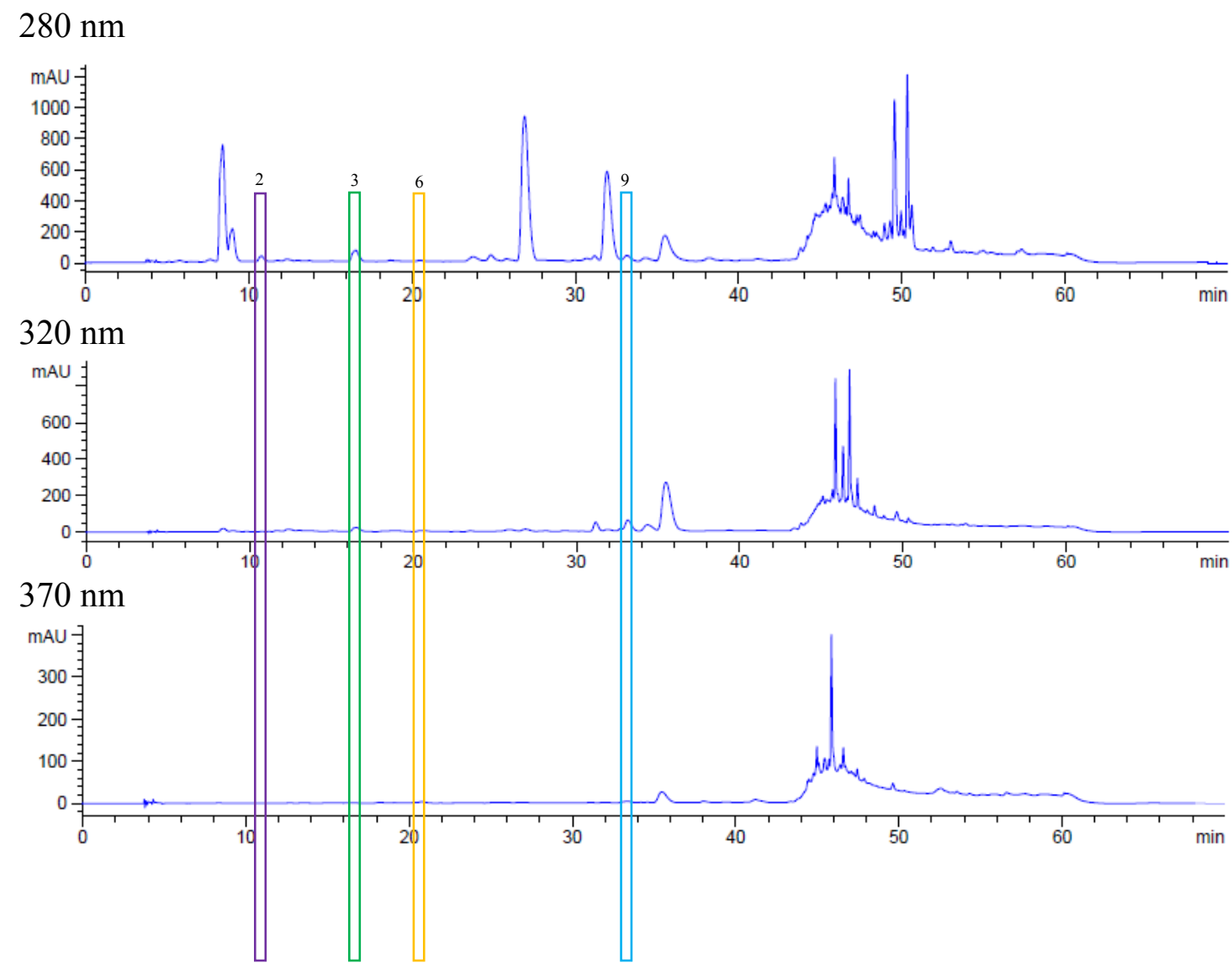

Figure 2 HPLC chromatograms of the RS pod dichloromethane extract revealed the presence of (2) protocatechuic acid, (3) $p$-hydroxybenzoic acid, (6) caffeic acid and, (9) ferulic acid. 


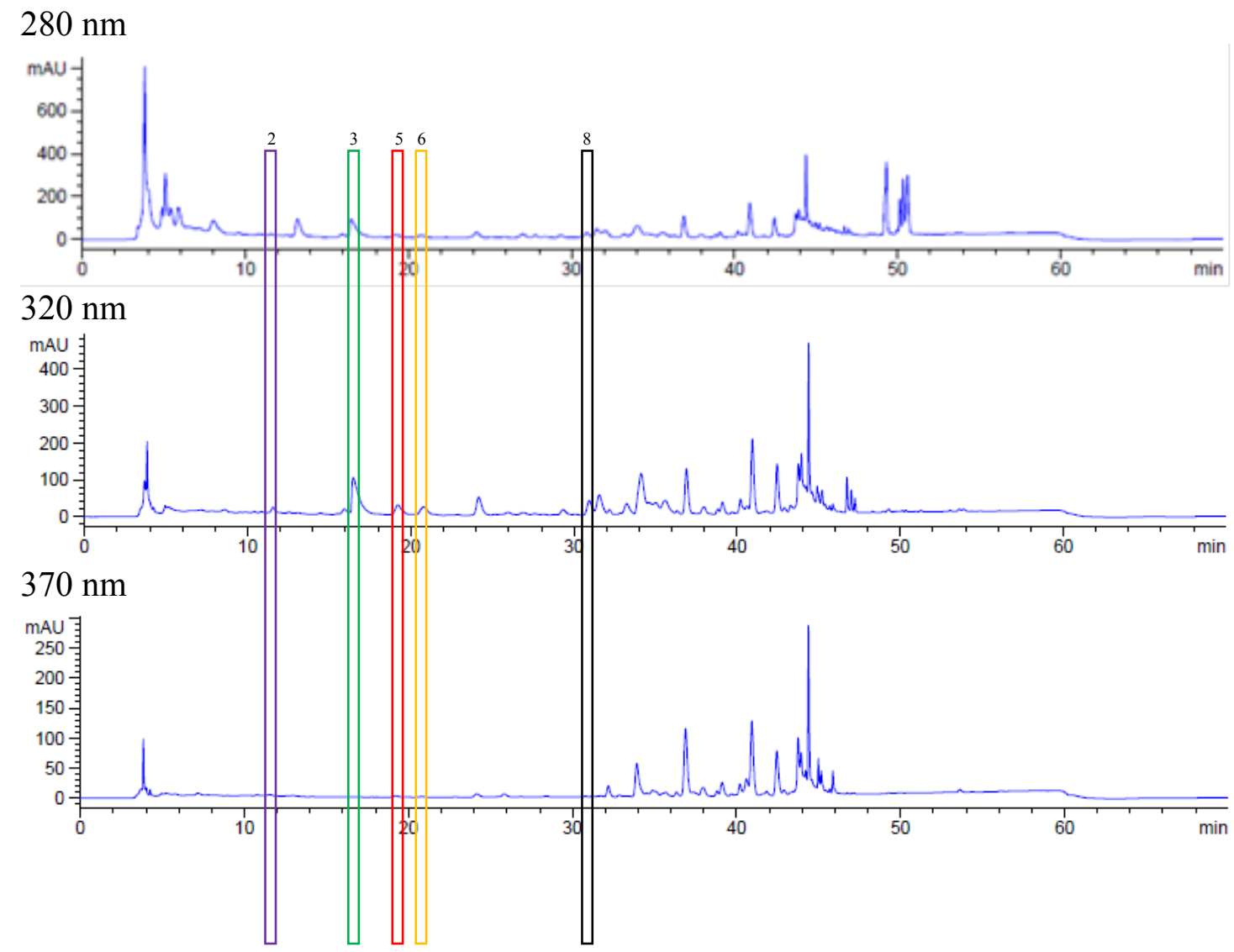

Figure 3 HPLC chromatograms of the RS pod aqueous extract illustrated the existence of (2) protocatechuic acid, (3) $p$-hydroxybenzoic acid, (5) vanillic acid, (6) caffeic acid and, (8) $p$-coumaric acid. 


\section{DMSO}

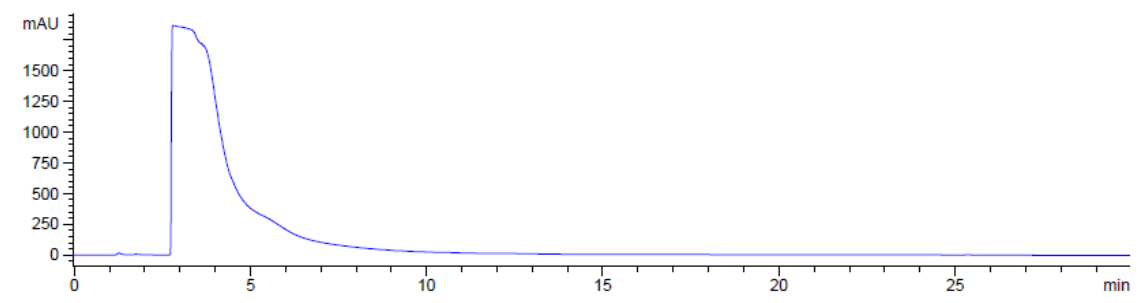

\section{Sulforaphene}

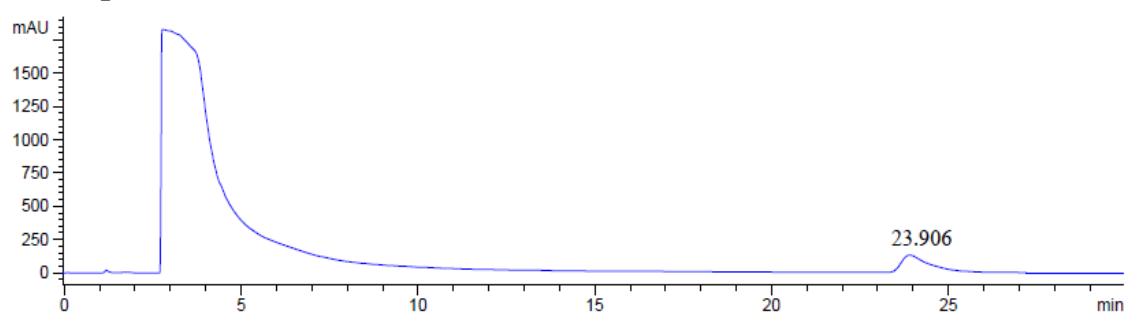

\section{Sulforaphane}

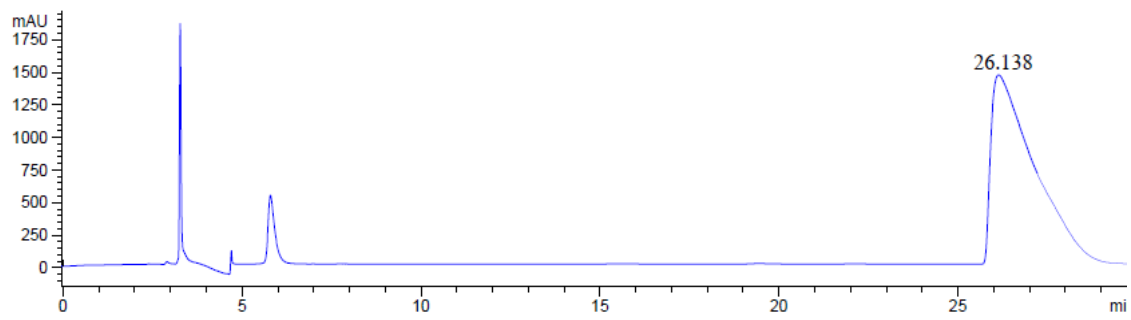

\section{RS pod DCM extract}

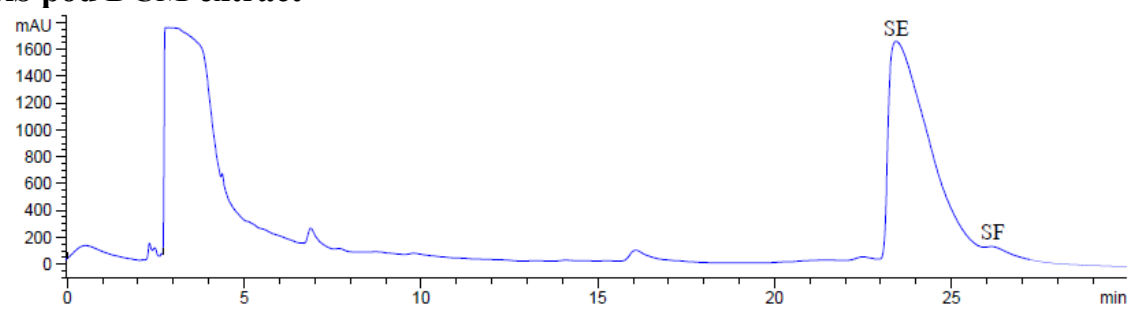

\section{RS pod aqueous extract}

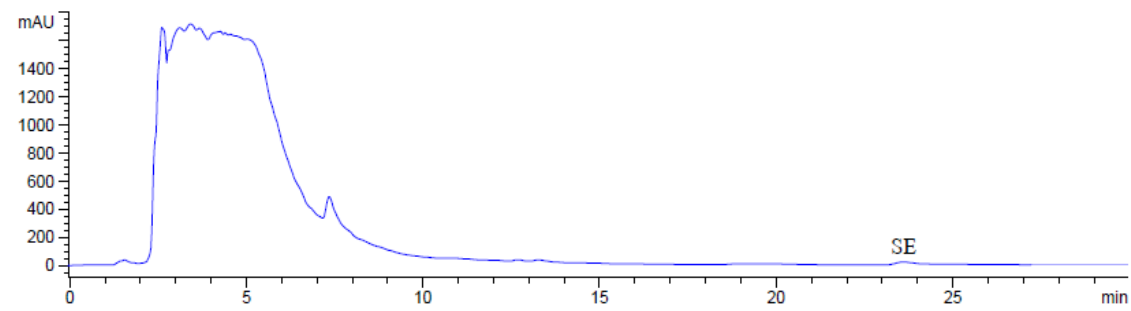

Figure 4 HPLC chromatogram of dimethyl sulfoxide (DMSO), standard sulforaphene, standard sulforaphane $(0.25 \mathrm{mg} / \mathrm{mL})$, and RS pod dichloromethane and aqueous extracts $(50 \mathrm{mg} / \mathrm{mL})$ detected at $210 \mathrm{~nm}$. 
Table 1 Quantification of phenolic compounds and isothiocyanates in the RS pod DCM and aqueous extracts.

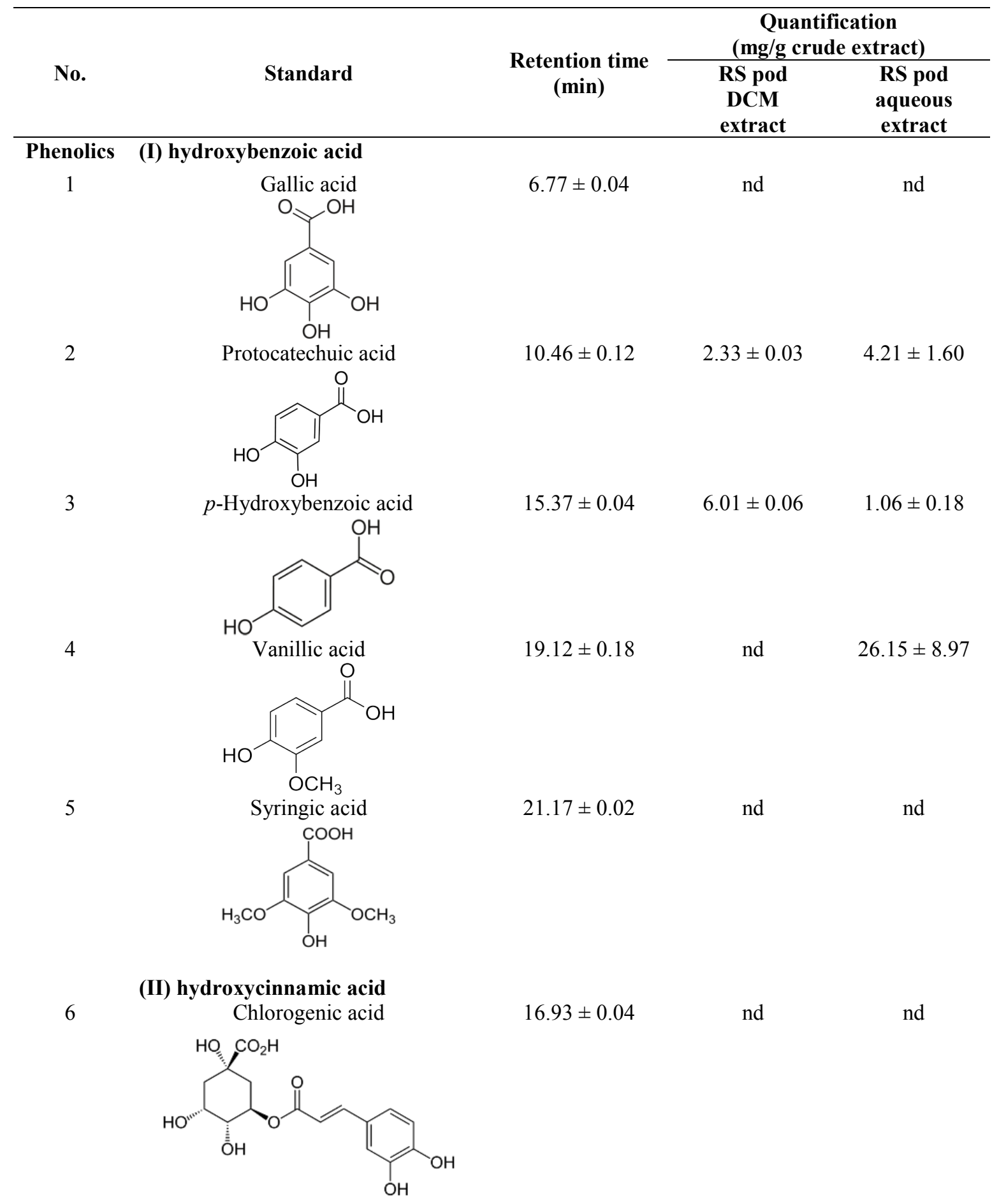




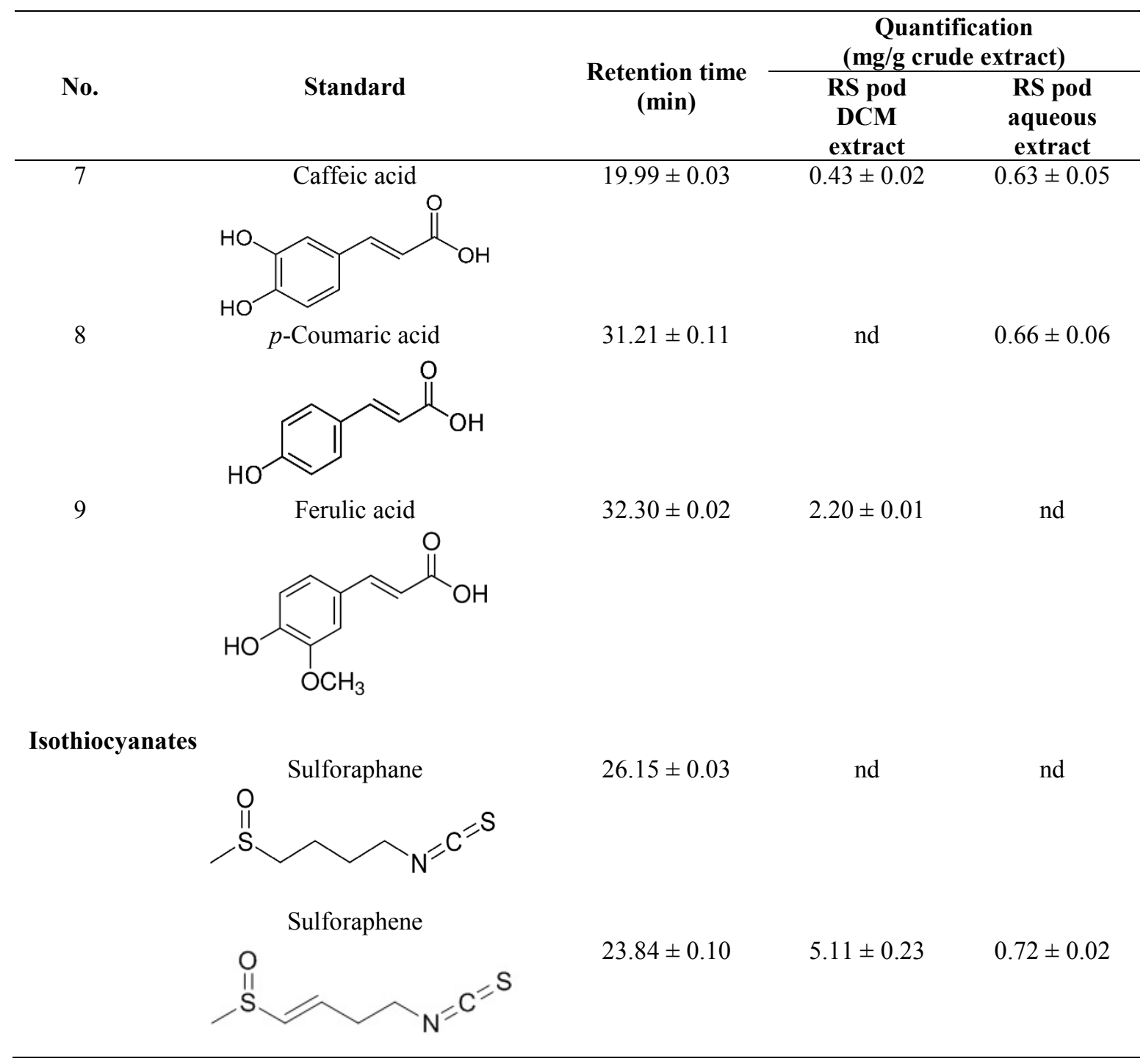

Data are represented as mean $\pm \mathrm{SD}(\mathrm{n}=3)$.

nd $=$ not determined

$\mathrm{DCM}=$ dichloromethane

\section{Antioxidant activity \\ DPPH radical scavenging activity}

DPPH is a stable chromogen radical with purple color detected at $517 \mathrm{~nm}$. DPPH scavenging assay is based on electron donation of antioxidants to neutralize DPPH radical. The decrease in color intensity in the presence of antioxidant can thus be measured [21]. The DPPH scavenging action of gallic acid, a positive control showed the $\mathrm{IC}_{50}$ value of $2.60 \pm 0.12 \mu \mathrm{g} / \mathrm{mL}$. The DCM extract $\left(\mathrm{IC}_{50}\right.$ value of $883.38 \pm$ $22.9 \mu \mathrm{g} / \mathrm{mL}$ ) had greater DPPH scavenging activity than the aqueous extract $\left(\mathrm{IC}_{50}\right.$ value of $1,160.49 \pm$ $22.30 \mu \mathrm{g} / \mathrm{mL}$ ) but lower than gallic acid. However, our study reports greater DPPH scavenging activity of the DCM extract than previous research which used the same solvent but with different extraction process [10]. In the previous study, RS pod was macerated in hexane to get hexane extract [10]. The dry residue 
was macerated with the respective dichloromethane and ethanol under the same steps as hexane extract preparation to obtain the dichloromethane extract and ethanol extract. One study reported that the phenolic compound which had high to low DPPH radical scavenging activity were gallic acid, caffeic acid, protocatechuic acid, ferulic acid, vanillic acid, $p$-coumaric acid, and $p$-hydroxybenzoic acid [22]. Thangboonjit et al. [23] reported the radical scavenging of DPPH for gallic acid to be higher than ferulic acid, caffeic acid, and p-coumaric acid. Ferulic acid, only found in the DCM extract, was previously reported to exert much greater activity than vanillic acid and $p$-coumaric acid, only found in the water extract. Therefore, ferulic acid may be partly attributed to radical scavenging of the DCM extract.

\section{Ferric reducing/antioxidant power (FRAP) assay}

The FRAP assay measures the reducing potential of an antioxidant reacting with a ferric tripyridyltriazine $\left[\mathrm{Fe}(\mathrm{III})(\mathrm{TPTZ})_{2}\right]^{3+}$ complex and producing a reduced form and blue colored ferrous tripyridyltriazine $\left[\mathrm{Fe}(\mathrm{II})(\mathrm{TPTZ})_{2}\right]^{2+}$ at low $\mathrm{pH}[19]$. The reducing properties of antioxidants are based on their ability to break the free radical chain through donating a hydrogen atom [24]. Results in Table 2 showed that gallic acid $(0.1$ to $10 \mu \mathrm{g} / \mathrm{mL})$ possessed FRAP value between $3.50 \pm 0.004$ to $232.24 \pm 0.005$ $\mu \mathrm{M} \mathrm{FeSO}_{4}$ equivalent. The FRAP value of the DCM extract was lower than the aqueous extract. At the same $2,000 \mu \mathrm{g} / \mathrm{mL}$ concentration, the DCM extract had FRAP value of $166.34 \pm 0.018 \mu \mathrm{M} \mathrm{FeSO}_{4}$ equivalent, while the aqueous extract had $218.27 \pm 0.010 \mu \mathrm{M} \mathrm{FeSO}$ equivalent. However, both extracts exerted lower FRAP value than gallic acid, a positive control. Phenolics have been known to act as antioxidant especially the 3-hydroxyl-containing phenolic compound [25,26]. Therefore, the higher detection of phenolics in the aqueous extract may play major role for its reducing property.

Table 2 The FRAP value of gallic acid, sulforaphane and sulforaphene, and the RS pod DCM and aqueous extracts.

\begin{tabular}{lcc}
\hline Compound & Concentration $(\boldsymbol{\mu g} / \mathbf{m L})$ & $\begin{array}{c}\text { FRAP value } \\
(\boldsymbol{\mu M} \text { FeSO }\end{array}$ \\
\hline Gallic acid & 0.1 & $3.50 \pm 0.004$ \\
& 0.5 & $8.21 \pm 0.006$ \\
& 1 & $23.83 \pm 0.006$ \\
& 2 & $42.93 \pm 0.001$ \\
Sulforaphene & 3 & $72.90 \pm 0.003$ \\
Sulforaphane & 4 & $100.14 \pm 0.004$ \\
DCM extract & 10 & $232.24 \pm 0.00523$ \\
& & inactive \\
& 100 & inactive \\
& 250 & $0.93 \pm 0.022$ \\
Aqueous extract & 500 & $10.60 \pm 0.008$ \\
& 1,000 & $37.07 \pm 0.026$ \\
& 2,000 & $85.17 \pm 0.033$ \\
& 100 & $166.34 \pm 0.018$ \\
& 250 & $19.36 \pm 0.004$ \\
& 500 & $46.54 \pm 0.006$ \\
& 1,000 & $86.90 \pm 0.004$ \\
& 2,000 & $176.71 \pm 0.002$ \\
\end{tabular}

Data is represented as mean $\pm \mathrm{SD}(\mathrm{n}=5)$.

Linear regression fit of FRAP standard curve $\left(\mathrm{Y}=0.0128 \mathrm{X}+0.0721, \mathrm{R}^{2}=0.9996\right)$ was obtained for $\mathrm{FeSO}_{4}$ at concentration ranged 3.6 to $89.9 \mu \mathrm{M}$. 


\section{Determination of tyrosinase inhibition activity}

Tyrosinase is the key enzyme in the first 2 steps of melanogenesis by activating the conversion of Ltyrosine to 3,4-dihydroxy-L-phenylalanin (L-DOPA) and to dopachrome [27]. The antimelanogenic activity was evaluated based on the in vitro inhibition of mushroom tyrosinase activity. Results (Figure 5) showed that kojic acid, a positive control possessed $50 \%$ inhibitory activity $\left(\mathrm{IC}_{50}\right.$ value) of $10.43 \pm$ $3.15 \mu \mathrm{g} / \mathrm{mL}$. In consideration of the rank order from strong to weak tyrosinase inhibitor at a range of initial concentration (less than $2 \mu \mathrm{g} / \mathrm{mL}$ ), sulforaphane possessed stronger inhibitory action than sulforaphene, kojic acid, gallic acid, DCM extract, and aqueous extract, respectively. The standard compounds-sulforaphene, sulforaphane and gallic showed low inhibitory activity and even using higher concentration no more inhibition was observed under the condition studied. The results showed that the DCM extract displayed greater \% inhibitory action than the aqueous extract. The percentage inhibitory action of DCM extract at $2,000 \mu \mathrm{g} / \mathrm{mL}$ was $42 \%$ and for aqueous extract at $4,000 \mu \mathrm{g} / \mathrm{mL}$ was $25 \%$. Due to high lipophilicity of sulforaphane and sulforaphene, their concentration could not be increased, not to mention their limit solubility under the condition studied. Therefore, the $\mathrm{IC}_{50}$ could not be determined.

A)

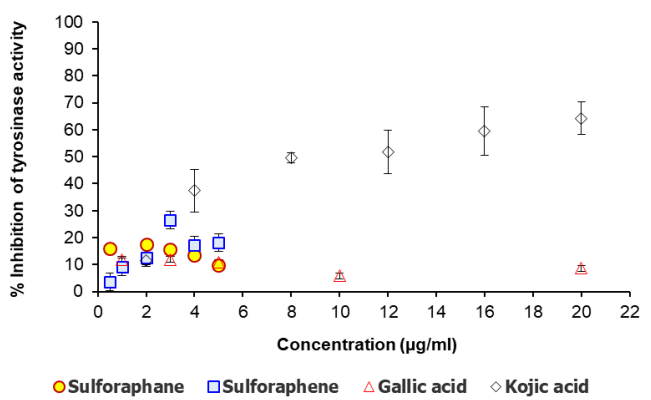

C)

\begin{tabular}{cccc}
\hline Compound & $\begin{array}{c}\text { Concentration } \\
(\boldsymbol{\mu g} / \mathbf{m L})\end{array}$ & $\begin{array}{c}\text { \% Tyrosinase } \\
\text { inhibition }\end{array}$ & $\mathbf{I C}_{\mathbf{5 0}}(\boldsymbol{\mu g} / \mathbf{m L})$ \\
\hline Sulforaphane & 2 & $17.5 \pm 5.2$ & $\mathrm{nd}$ \\
Sulforaphene & 2 & $12.5 \pm 7.7$ & nd \\
Kojic acid & 2 & $11.6 \pm 1.7$ & $10.43 \pm 3.15$ \\
Gallic acid & 3 & $11.9 \pm 1.5$ & $\mathrm{nd}$ \\
RS pod DCM extract & 2 & $11.4 \pm 0.9$ & $\mathrm{nd}$ \\
RS pod aqueous extract & 2 & $8.6 \pm 1.3$ & $\mathrm{nd}$ \\
\hline
\end{tabular}

B)

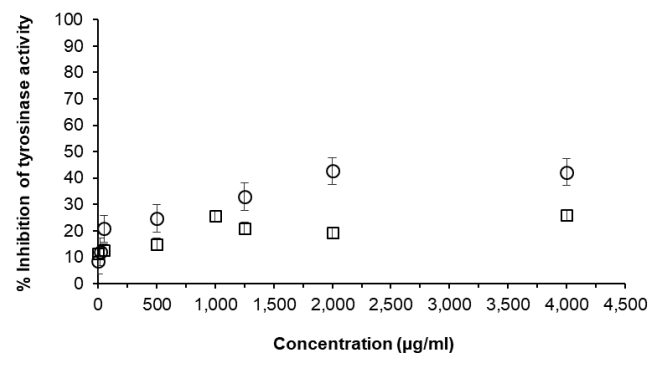

aRS pod aqueous extract ORS pod DCM extract

Figure 5 Percent tyrosinase inhibitory activity of A) sulforaphane, sulforaphene, gallic acid, and kojic acid, B) RS pod DCM extract and aqueous extract, and C) the inset table expressed the \%tyrosinase inhibitory activity of each test samples at the same concentration except gallic acid. Data are expressed as mean $\pm \mathrm{SD}$ from triplication ( $\mathrm{nd}=$ cannot be determined).

Previously, sulforaphane exerted its anti-melanogenesis and inhibition of tyrosinase expression in B16 mouse melanoma cells [28]. Sulforaphane inhibited tyrosinase activity up to $80 \%$ at the maximum concentration $5 \mu \mathrm{M}$ [28]. Sulforaphane inhibited phosphorylated p38 activated MITF which further decreased melanogenesis. Moreover, sulforaphane increased the expression of ERK protein that further suppressed the melanogenesis [28]. Several studies reported the tyrosinase inhibition of phenolics such as ferulic acid and $p$-coumaric acid [23], but not for vanillic acid [29]. It should be noted that sulforaphane, ferulic acid was only found in DCM extract, while vanillic was only found in aqueous extract. Hence, sulforaphane along with the other phenolics such as ferulic acid may attribute to tyrosinase inhibitory effect in the DCM extract. Although aqueous extract contained vanillic acid which did not have any 
tyrosinase inhibitory effect, there might be other undetected substances that may attribute to its relative low activity.

\section{Conclusions}

The DCM extract of Raphanus sativus L. var. caudatus has greater DPPH radical scavenging and anti-tyrosinase activity than the aqueous extract. The aqueous extract possesses greater ferric reducing/antioxidant power than the DCM extract. It is evident that different solvent extraction of RS yields different phytochemical constituents leading to different degree of activity tested. This is the first report of tyrosinase activity of the RS pod extract. It confirms that RS is a potential source of compound that possess antioxidant and anti-tyrosinase activity which may offer the reduction of wrinkles and lightening effect in cosmetic product. However, more separation or fractionation to get the concentrated active ingredient may be required to increase the strength of action.

\section{Acknowledgements}

NW is grateful to the Faculty of Pharmaceutical Sciences for the financial support for this project in the year of 2017 .

\section{References}

[1] B Desmedt, P Courselle, JO De Beer, V Rogiers, M Grosber, E Deconinck and KD Paepe. Overview of skin whitening agents with an insight into the illegal cosmetic market in Europe. $J$. Eur. Dermatol. Venereol. 2016; 30, 943-50.

[2] GF Sun, WT Hu, ZH Yuan, BA Zhang and H Lu. Characteristics of mercury intoxication induced by skin-lightening products. Chin. Med. J.-Peking, 2017; 130, 3003-4.

[3] C Couteau and L Coiffard. Overview of skin whitening agents: drugs and cosmetic products. Cosmetics 2016; 3, 27.

[4] SN Chohan, M Suhail, S Salman, UM Bajwa, M Saeed, S Kausar and T Suhail. Facial abuse of topical steroids and fairness creams: A clinical study of 200 patients. J. Pak. Asso. Dermatol. 2014; 24, 204-11.

[5] T Songsak and G Lockwood. Glucosinolates of seven medicinal plants from Thailand. Fitoterapia 2002; 73, 209-16.

[6] P Pocasap, N Weerapreeyakul and S Barusrux. Cancer preventive effect of Thai rat-tailed radish (Raphanus sativus L. var. caudatus Alef). J. Funct. Food. 2013; 5, 1372-81.

[7] S Sangthong, N Weerapreeyakul, M Lehtonen, J Leppanen and J Rautio. High-accuracy mass spectrometry for identification of sulphur-containing bioactive constituents and flavonoids in extracts of Raphanus sativus var. caudatus Alef (Thai rat-tailed radish). J. Funct. Food. 2017; 31, 237-47.

[8] S Sangthong, N Weerapreeyakul and S Barusrux. Antiproliferative effect of Raphanus sativus L. var. caudatus Alef in human breast MCF-7 and human lung SK-LU1 adenocarcinoma cell lines. Isan J. Pharm. Sci. 2015; 10, 75-81.

[9] S Sangthong, N Weerapreeyakul and S Barusrux. Cell survival inhibitory effect of Raphanus sativus v. caudatus Alef extracts against non-resistant HepG2 and resistant HepG2 hepatocellular carcinoma. In: Proceedings of the $34^{\text {th }}$ National Graduate Research Conference, Khon Kaen University, Khon Kaen, Thailand. 2016, p. 80-3.

[10] T Charoonratana, S Settharaksa, F Madaka and T Songsak. Screening of antioxidant activity and total phenolic content in Raphanus sativus pod. Int. J. Pharm. Pharmaceut. Sci. 2014; 6, 224-6.

[11] A Siddiq and I Younus. Screening in-vitro antifungal activity of Raphanus sativus L. var. caudatus. World J. Pharm. Pharmaceut. Sci. 2015; 4, 429-37.

[12] I Younus and A Siddiq. Behavioral evidence of antidepressant-like activity of Raphanus sativus L. var. caudatus in mice. Afr. J. Tradit. Complement. Altern. Med. 2017; 14, 142-6. 
[13] I Younus and A Siddiq. In-Vitro antileishmanial activity of Raphanus sativus L. var. caudatus. J. Basic Appl. Sci. 2016; 12, 242-4.

[14] R Jakmatakul, R Suttisri and P Tengamnuay. Evaluation of antityrosinase and antioxidant activities of Raphanus sativus root: Comparison between freeze-dried juice and methanolic extract. Thai J. Pharmaceut. Sci. 2009; 33, 22-30.

[15] M Jahangir, HK Kim, YH Choi and R Verpoorte. Health-affecting compounds in Brassicaceae. Compr. Rev. Food Sci. Food Saf. 2009; 8, 31-43.

[16] S.Sangthong and N Weerapreeyakul. Simultaneous quantification of sulforaphene and sulforaphane by reverse phase HPLC and their content in Raphanus sativus L. var. caudatus Alef extracts. Food Chem. 2016; 201, 139-44.

[17] O Kaisoon, S Siriamornpun, N Weerapreeyakul and N Meeso. Phenolic compounds and antioxidant activities of edible flowers from Thailand. J. Funct. Food. 2011; 3, 88-99.

[18] W Brand-Williams, ME Cuvelier, and C Berset. Use of a free radical method to evaluate antioxidant activity. LWT-Food Sci. Technol. 1995; 28, 25-30.

[19] IF Benzie and JJ Strain. The ferric reducing ability of plasma (FRAP) as a measure of "antioxidant power": The FRAP assay. Anal. Biochem. 1996; 239, 70-6.

[20] M Srisayam, N Weerapreeyakul, S Barusrux, W Tanthanuch and K Thumanu. Application of FTIR microspectroscopy for characterization of biomolecular changes in human melanoma cells treated by sesamol and kojic acid. J. Dermatol. Sci. 2014; 73, 241-50.

[21] F Shahidi and Y Zhong. Measurement of antioxidant activity. J. Funct. Food. 2015; 18, 757-81.

[22] M Karamac, A Kosinska and RB Pegg. Comparison of radical-scavenging activities for selected phenolic acids. Pol. J. Food Nutr. Sci. 2005; 14, 165-70.

[23] W Thangboonjit, T Pluemsamran and U Panich. Comparative evaluation of antityrosinase and antioxidant activities of dietary phenolics and their activities in melanoma cells exposed to UVA. Siriraj Med. J. 2014; 66, 5-10.

[24] PD Duh, PC Du and GC Yen. Action of methanolic extract of mung bean hulls as inhibitors of lipid peroxidation and non-lipid oxidative damage. Food Chem. Toxicol. 1999; 37, 1055-61.

[25] S Nishaa, M Vishnupriya, J Sasikumar, PC Hephzibah and V Gopalakrishnan. Antioxidant activity of ethanolic extract of Maranta arundinacea L. tuberous rhizomes. Asian J. Pharmaceut. Clin. Res. $2012 ; \mathbf{5}, 85-8$.

[26] K Csepregi, S Neugart, M Schreiner and E Hideg. Comparative evaluation of total antioxidant capacities of plant polyphenols. Molecules 2016; 21, 208.

[27] YJ Kim and H Uyama. Tyrosinase inhibitors from natural and synthetic sources: Structure, inhibition mechanism and perspective for the future. Cell Mol. Life Sci. 2005; 62, 1707-23.

[28] I Shirasugi, M Kamada, T Matsui, Y Sakakibara, MC Liu and M Suiko. Sulforaphane inhibited melanin synthesis by regulating tyrosinase gene expression in B16 mouse melanoma cells. Biosci. Biotechnol. Biochem. 2010; 74, 579-82.

[29] M Miyazawa, T Oshima, K Koshio, Y Itsuzaki and J Anzai. Tyrosinase inhibitor from black rice bran. J. Agric. Food Chem. 2003; 51, 6953-6. 